\title{
SISTEM TEKANAN MEKANIK BERBASIS MIKROKONTROLER AT-MEGA 16 UNTUK PEMBUATAN KERUPUK PELOMPONG GUNA MENUNJANG PRODUKSI HOME INDUSTRY BAROKAH DI TUBAN JAWA TIMUR
}

\author{
Adibatul Ardianto ${ }^{1} \&$ Dessy Irmawati ${ }^{1}$ \\ Universitas Negeri Yogyakarta $^{1}$ \\ e-mail: adibatulardianto1995@gmail.com
}

\begin{abstract}
ABSTRAK
Tujuan pembuatan alat ini adalah untuk mendapatkan rancang bangun hardware, program perangkat lunak dan unjuk kerja Sistem tekanan mekanik berbasis mikrokontroler AT-Mega 16 untuk pembuat kerupuk pelompong guna menunjang proses produksi home Industry Barokah di Tuban Jawa Timur.Pembuatan sistem tekanan mekanik berbasis mikrokontroler AT-Mega 16 terdiri dari beberapa tahapan yaitu identifikasi kebutuhan, analisa kebutuhan, blok diagram sistem, perancangan sistem, langkah pembuatan alat, diagram alir program, pengujian alat dan pengambilan data. Pembuatan frame menggunakan besi jenis tabung, siku dan kanal C. Alat ini menggunakan komponen sistem minimum Atmega16, driver motor BTS7960 sebagai pengatur putaran dan kecepatan motor, dongkrak mekanik yang sudah di modifikasi dengan motor DC digunakan sebagai penggerak untuk menekan adonan kerupuk, LCD Displays 16x2 sebagai media penampil yang terdapat perintah kecepatan yang diinginkan, push button berfungsi sebagai pemberi masukan data yang akan diolah pada kontroler ATmega16 lalu akan menggerakan putaran motor DC. Berdasarkan hasil pengujian yang sudah dilakukan, diperoleh hasil bahwa sistem tekanan mekanik berbasis mikrokontroler AT-Mega 16 berfungsi dengan baik dan sesuai dengan kondisi di home industry Barokah, keunggulan sistem ini cukup 1 orang untuk mencetak (membuat) kerupuk pelompong, dibandingnkan dengan alat tradisional yang ada di home industry Barokah untuk mencetak perlu 2 orang untuk mengerjakan, secara efesiensi waktu sistem tekanan mekanik ini lebih cepat dengan selisih rata-rata 3 menit untuk menyelesaikan cetakan per tabung adonan.
\end{abstract}

Kata kunci: pengembangan, pengkondisi sinyal, photodioda, instrumentasi

\section{PENDAHULUAN}

Dewasa ini di Indonesia telah banyak bermunculan makanan ringan baik bentuk maupun rasa. Kerupuk merupakan salah satu makanan ringan yang sangat digemari oleh masyarakat Indonesia. Permintaan terhadap kerupuk pun masih cenderung sangat tinggi di Indonesia dari kalangan bawah hingga kalangan atas senang menikmati makanan ini. Pada umumnya kerupuk terbuat dari tepung terigu dengan tepung tapioka yang dipadukan dengan perasa seperti udang, ikan tengiri, dan juga pewarna agar tampilannya terlihat menarik.

Permintaan masyarkat yang relatif tinggi membuat bahan pangan ini tidak pernah sepi. Khususnya masyarakat Indonesia mulai dari kalangan rendah sampai menengah keatas sangat menggemari bahan pangan ini. Oleh karena itu, untuk menarik minat konsumen beberapa pabrik membuat berbagai macam variasi kerupuk guna meningkatkan nilai jual yang tinggi.

Banyaknya industri kerupuk yang mati atau kalah persaingan karena tidak seimbangnya antara permintaan produksi dan lama produksi. Mesin pencetak kerupuk yang masih cenderung tradisional membatasi proses produksi. Home industry pembuatan kerupuk pelompong Barokah di Desa Sambonggede Kecamatan Merakurak Kabupaten Tuban Jawa Timur, pembuatan kerupuk masih dilakukan secara tradisional, sistem pembuatanya melalui press yang ditekan dengan kayu dan dibutuhkan 2 orang untuk mencetak kerupuk pelompong.

Kelebihan sistem tekanan mekanik untuk pembuatan kerupuk pelompong adalah dapat menghemat waktu dan tenaga manusia, untuk sistem ini hanya 1 orang untuk mencetak kerupuk pelompong sehingga segi 
waktu lebih cepat. Alat tradisional tidak mampu memenuhi permintaan pasar karena setiap minggu memproduksi 4 kuintal, sedangkan permintaan pasar mencapai 1 hingga 2 kuintal dalam 3 hari, sehingga dengan mesin ini diharapkan memenuhi permintaan pasar.

Pembuatan sistem tekanan mekanik berbasis mikrokontoler AT-Mega 16 untuk pembuatan kerupuk pelompong, merupakan solusi untuk mengatasi permasalahan di atas dan dapat menunjang proses produksi di home industy Barokah di Desa Sambonggede Kecamatan Merakurak Kabupaten Tuban Jawa Timur, agar produksi lebih meningkat.

Berdasarkan permasalahan ada 3 identifikasi masalah (1) Pembuatan kerupuk pelompong masih menggunakan cara tradisonal sehingga kurang efisien. (2) Secara kuantitas, produksi kerupuk tidak dapat memenuhi permintaan konsumen. (3) Belum terciptanya sistem tekanan mekanik untuk mencetak kerupuk pelompong.

Rumusan masalah dari pembuatan alat ini ada 3 meliputi (1) Bagaimana mengembangkan perangkat keras sistem tekanan mekanik berbasis Mikrokontroler ATMega 16 untuk pembuatan kerupuk pelompong?. (2) Bagaimana mengembangkan perangkat lunak sistem tekanan mekanik berbasis Mikrokontroler AT-Mega 16 untuk pembuatan kerupuk pelompong?.

Bagaimana unjuk kerja dan kelebihan sistem tekanan mekanik berbasis Mikrokontroler ATMega 16 untuk pembuatan kerupuk pelompong?.

Pembuatan Alat ini meliputi 3 tujuan (1) Menerapkan sistem tekanan mekanik berbasis mikrokontoler AT-Mega 16 untuk pembuatan kerupuk pelompong guna menunjang proses produksi di home industy Barokah. (2) Merealisasikan perangkat lunak bahasa $\mathrm{C}$ untuk pemrograman Mikrokontoler AT-Mega
16 mesin pembuat kerupuk pelompong menggunakan Sistem tekanan mekanik. (3) Mengetahui unjuk kerja alat dan kelebihan sistem tekanan mekanik berbasis mikrokontoler AT-Mega 16 untuk pembuatan kerupuk pelompong guna menunjang proses produksi di home industy Barokah.

Kerupuk Pelompong adalah kerupuk yang terbuat dari bahan baku tepung tapioka dan tepung terigu. Salah satu pembuat kerupuk pelompong Barokah di Tuban Jawa Timur, rasanya yang gurih dan renyah, banyak di gemari oleh masyarakat sekitar Tuban. Seperti pada gambar 1.

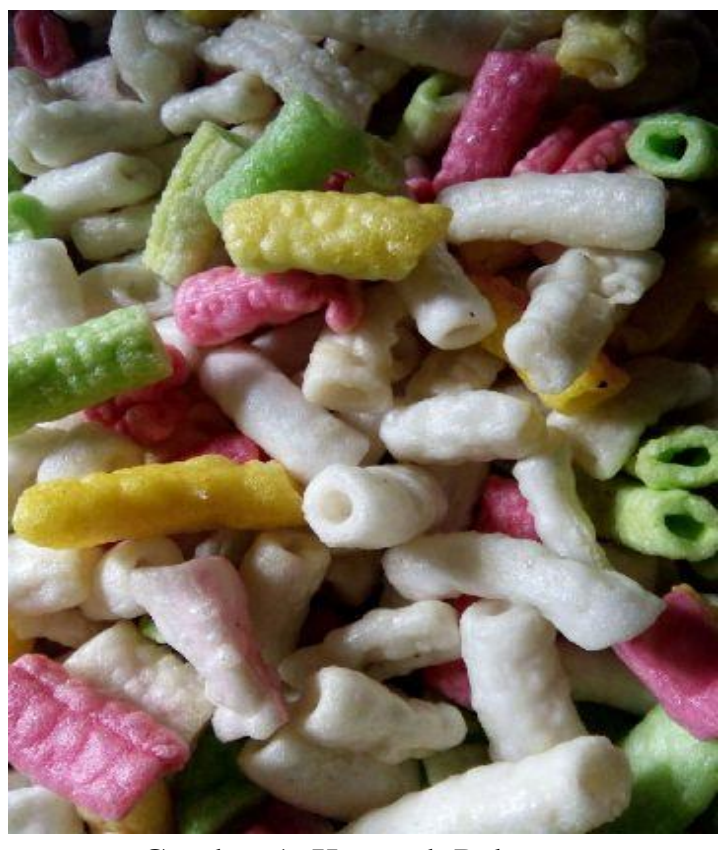

Gambar 1. Kerupuk Pelompong

Dongkrak merupakan salah satu pesawat pengangkat yang digunakan untuk mengangkat beban ke posisi yang dikehendaki dengan gaya yang kecil (Syahe, 2014), Dongkrak mekanik contohnya dongkrak ulir menggunakan mekanisme ulir seperti baut untuk meninggikan titik pusat penampang. Seperti pada gambar 2. 


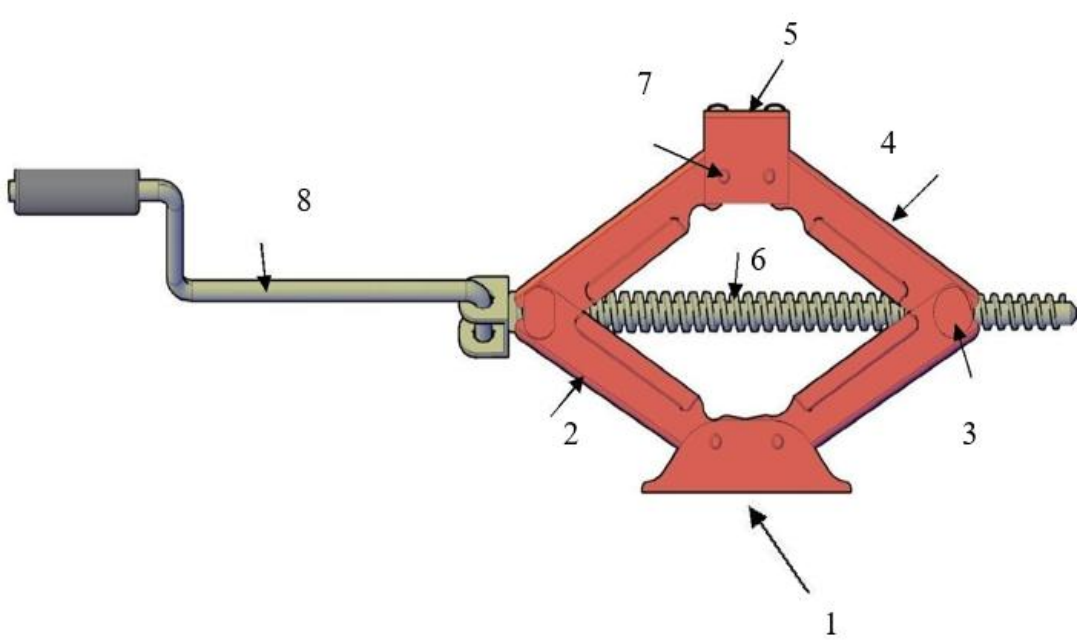

Keterangan gambar:

1.Kaki penyangga (foot)

2.Lengan bawah (lower arms)

3.Nuts

4.Lengan atas (upper arms)

5.Penyangga atas (top bracket)

6.Poros ulir (screw)

7.Pins

8.Crank/handle

Gambar 2. Dongkrak Ulir Mekanik

Prinsip kerja dongkrak ulir mekanik saat menaikkan beban yaitu terdiri atas langkahlangkah diantaranya: (1) pada saat handle diputar searah jarum jam, maka poros ulir akan ikut berputar mengikuti putaran handle, dan pada poros ulirnya dihubungkan nuts; (2) Nuts dan poros ulir akan berkerja seperti halnya sepasang baut dan mur yang dapat bergerak maju sesuai arah putaran; (3) Bergeraknya ulir mengakibatkan rangka lengan atas dan bawah saling mendekat, sehingga ketinggian dongkrak pun berubah; dan (4) Bertambahnya tinggi dongkrak mengakibatkan beban yang ada diatas penyangga atas pun terangkat. Prinsip kerja dongkrak ulir mekanik saat menurunkan beban yaitu terdiri atas langkah-langkah diantaranya: (1) Pada saat handle diputar berlawanan arah jarum jam, maka poros ulir akan ikut berputar mengikuti putaran handle dan pada poros ulirnya dihubungkan nuts; (2) Nuts dan poros ulir akan berkerja seperti halnya sepasang baut dan mur yang dapat bergerak mundur sesuai arah putarannya; (3) Bergeraknya ulir mengakibatkan rangka lengan atas dan bawah saling menjauh, sehingga ketinggian dongkrak pun berubah; dan (4) Berkurangnya tinggi dongkrak mengakibatkan beban yang ada diatas penyangga atas pun akan turun.

\section{METODE}

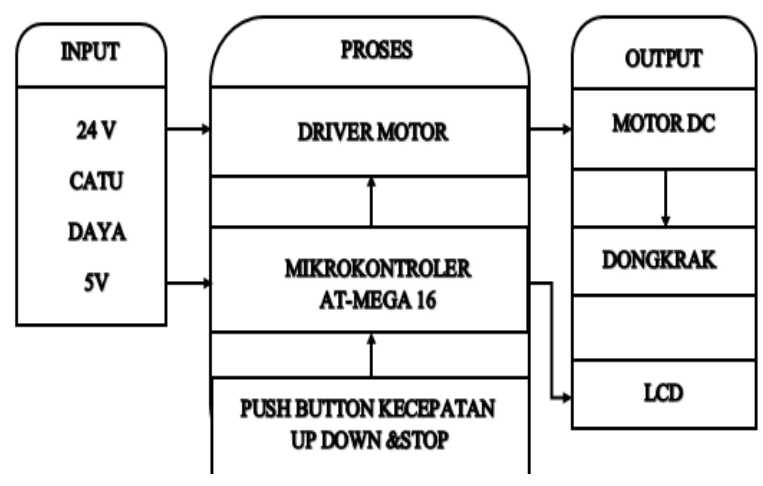

Gambar 3. Blok Diagram Sistem

Gambar 3 merupakan blok diagram rangkaian sistem keseluruhan proses yang diaplikasiakan pada Sistem Tekanan Mekanik Berbasis Mikrokontroler AT-Mega 16 untuk Pembuat Kerupuk Pelompong Guna Menunjang Produksi Home Industry Barokah di Tuban Jawa Timur: Berdasarkan Gambar 2 dapat dijelaskan bagaimana masukan perintah pemilihan kecepatan melalui push button Up atau Down, kemudian data tersebut akan diolah oleh mikrokontroler. Masukan data kemudian mengaktifkan driver motor BTS 7960 untuk menggerakan kecepatan dan arah putaran motor juga akan mengaktifkan button yang sudah dipilih. Proses yang berlangsung kemudian akan ditampilkan pada LCD Display. LCD Display akan menampilkan 
kecepatan yang dipilih dan gerakan motor yang telah ditentukan oleh operator. Mesin akan berhenti jika push button stop ditekan.

Perancangan frame terdiri atas: (1) Membuat desain frame terlebih dahulu dan tabung cetakan; (2) Memotong besi yang telah ditentukan panjangnya. Dengan tinggi 1 meter sebagai tiang penyangga, lebar $50 \mathrm{~cm}$, dan panjang 1 meter dan tabung cetakan mempunyai diamater $14 \mathrm{~cm}$ panjang tabung 30cm; (3) menyambungkan potongan tersebut dengan cara dilas dan membentuk seperti meja yang nantinya akan dibuat frame; (4) Kemudian memasang tabung cetakan di atas frame tersebut; (5) Hasil rancangan frame bisa dilihat pada gambar 4; dan (6) Supaya hasil lebih menarik dan tahan karat rangakain frame tersebut dilapisi dengan cat besi.

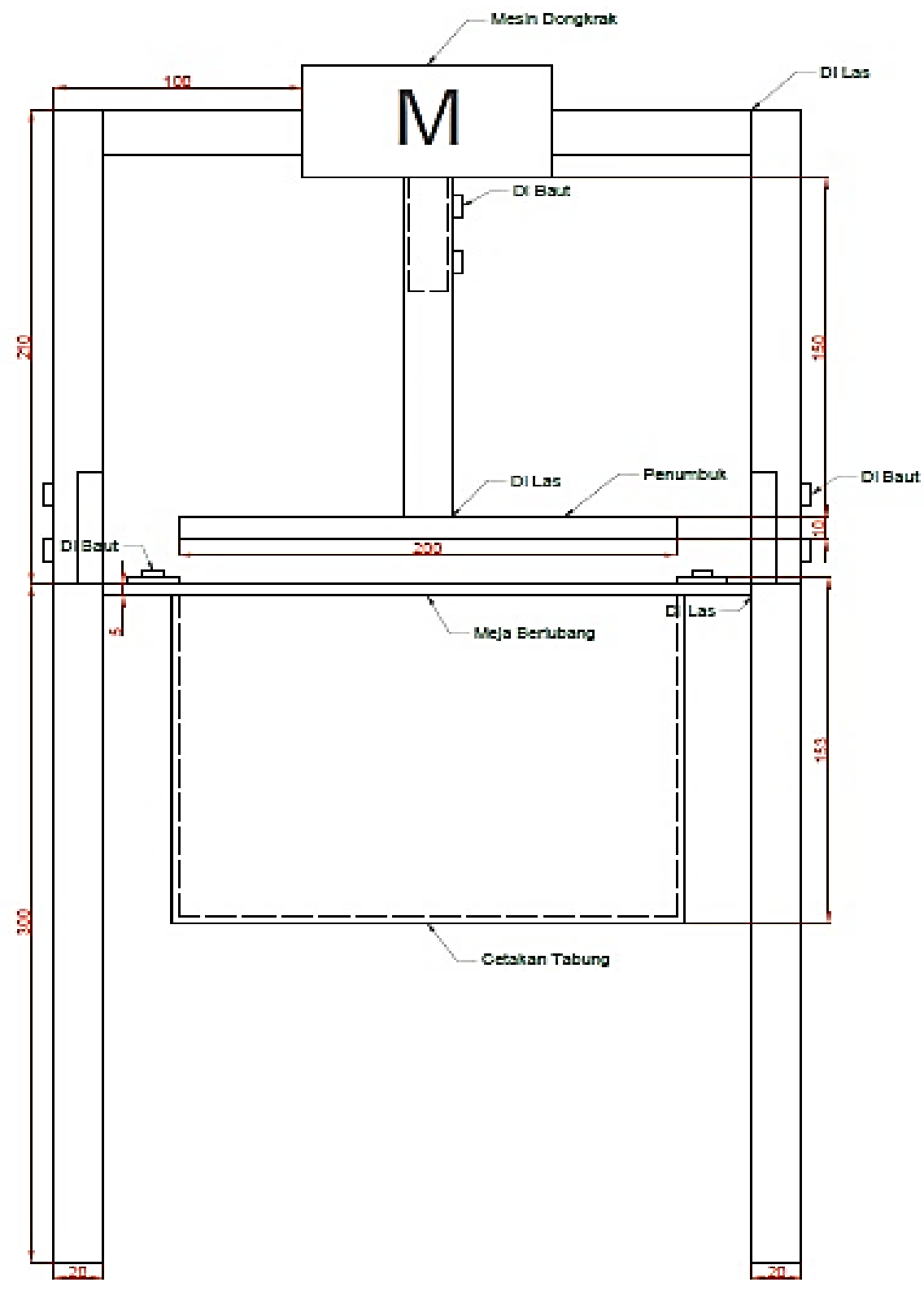

Gambar 4. Desain Rancangan Frame

Perancangan perangkat lunak program utama ini secara garis besar bertujuan untuk mengatur kerja sistem seperti inisialisasi register $\mathrm{I} / \mathrm{O}$ dan variabel, pembacaan hasil sensor, proses pengaturan sinyal kontrol. Program utama berperan sebagai jantung perangkat lunak yang akan mengatur keseluruhan operasi yang melibatkan fungsi- 
fungsi pendukung. Fungsi-fungsi pendukung akan melakukan kerja khusus sesuai kebutuhan dari program utama. Diagram alir

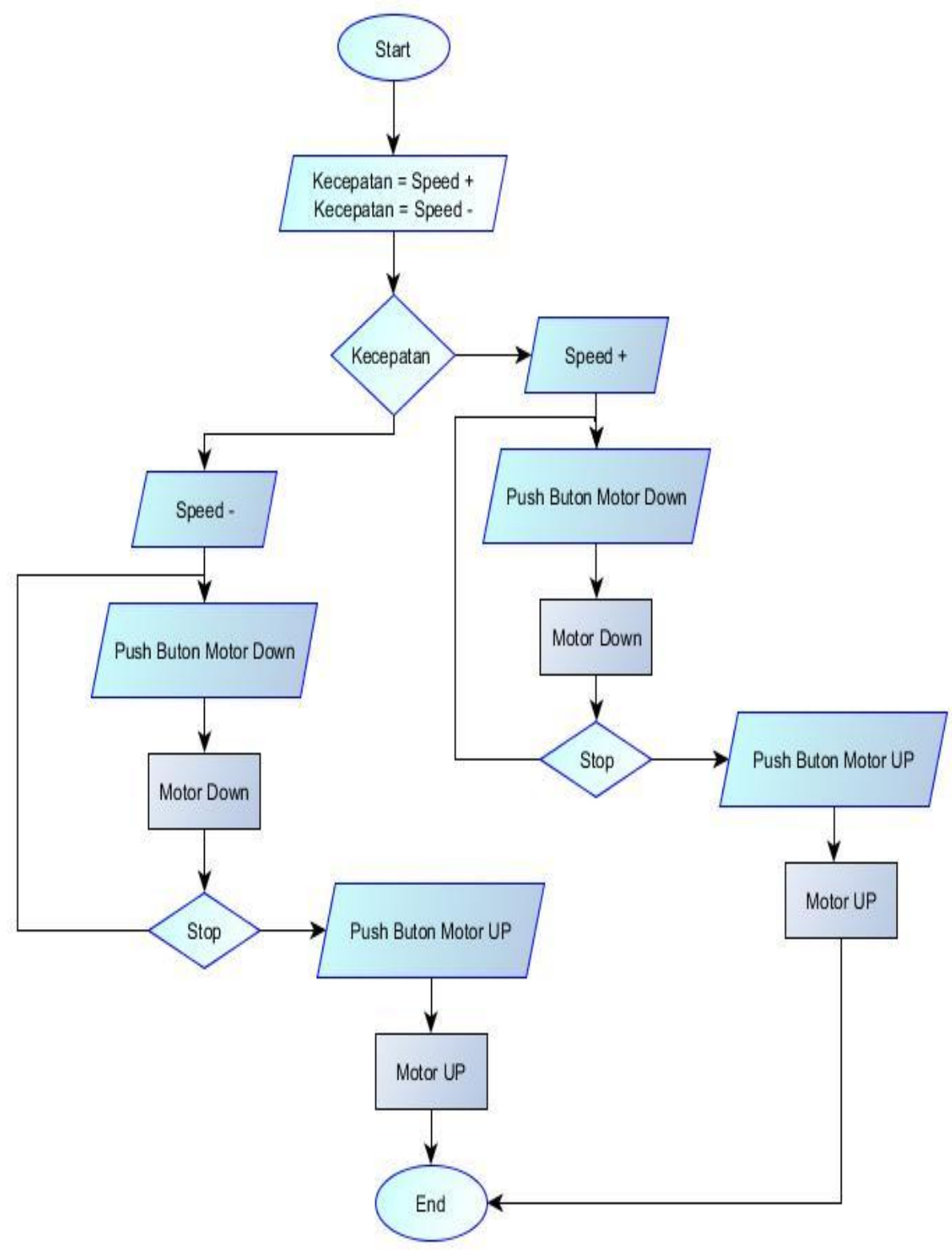

Gambar 5. Flow Chart program utama dapat dilihat pada Gambar 5. diagram alir pada software. 
Tabel 1 merupakan pengukuran tegangan regulator untuk keluaran dari IC regulator LM7824 adalah $24 \mathrm{~V}$ pada saat tanpa beban dan saat dengan beban tegangan keluaran menjadi $23,2 \mathrm{~V}$, sehingga memiliki selisih error sebesar 0,8 V. Sedangkan pengukuran tegangan regulator untuk keluaran dari IC regulator LM7805 adalah $5 \mathrm{~V}$ pada saat tanpa beban dan saat dengan beban tegangan keluaran menjadi $4,8 \mathrm{~V}$, sehingga memiliki selisih error sebesar $0,2 \mathrm{~V}$. Selanjutnya dilakukan pengujian tegangan mikrokontroler seperti pada Tabel 2.

Tabel 2. Pengujian Tegangan Mikrokontroler

\begin{tabular}{cccc}
\hline Pengukuran & $\begin{array}{c}\mathrm{V} \text { in } \\
\text { (VDC) }\end{array}$ & $\begin{array}{c}\mathrm{V} \\
\text { output } \\
\text { (VDC) }\end{array}$ & $\begin{array}{c}\text { error } \\
\%\end{array}$ \\
\hline Tanpa Beban & $4,8 \mathrm{~V}$ & $4,8 \mathrm{~V}$ & $0 \%$ \\
Dengan Beban & $4,8 \mathrm{~V}$ & $4,6 \mathrm{~V}$ & $4 \%$ \\
\hline
\end{tabular}

Pada tabel 2 merupakan pengukuran tegangan keluaran mikrokontroler adalah 4,8 pada saat tanpa beban dan saat dengan beban tegangan keluaran menjadi $4,6 \mathrm{~V}$, sehingga memiliki selisih error sebesar $0,2 \mathrm{~V}$. Selanjutnya dilakukan pengukuran pada tegangan motor DC, dengan hasil pada saat kecepatan 0-255 saat tanpa beban dan dengan beban dapat dilihat pada Tabel 3 .

Tabel 3. Pengujian Tegangan Motor DC

\begin{tabular}{cccc}
\hline No & $\begin{array}{c}\text { Kecepatan } \\
\text { PWM }\end{array}$ & \multicolumn{2}{c}{ V output (VDC) } \\
& Tanpa Beban Dengan Beban \\
\hline 1 & 0 & 0 & 0 \\
2 & 50 & 2,4 & 2 \\
3 & 100 & 4.4 & 4 \\
4 & 150 & 8 & 7 \\
5 & 200 & 13 & 12 \\
6 & 255 & 23 & 19,5 \\
\hline
\end{tabular}

Pengujian hasil kerja dilakukan untuk mengetahui kualitas dari kinerja Sistem Tekanan Mekanik Berbasis Mikrokontroler AT-Mega 16 Untuk Pembuat Kerupuk Pelompong Guna Menunjang Produksi Home Industry Barokah di Tuban Jawa Timur. Pengujian ini bertujuan untuk mengetahui hasil produksi kerupuk pelompong apakah hasilnya sesuai harapan.

Tabel 4. Hasil uji mesin tradisional dan Alat.

\begin{tabular}{ccc}
\hline Percobaan & $\begin{array}{c}\text { Tradisional } \\
\text { (waktu) }\end{array}$ & Alat (waktu) \\
\hline 1 & 10.10 menit & 7.07 menit \\
2 & 10.46 menit & 7.05 menit \\
3 & 10.03 menit & 7.39 menit \\
4 & 14.07 menit & 8.49 menit \\
5 & 9.53 menit & 8.55 menit \\
\hline
\end{tabular}

Pada Tabel 4 pengujian dilakukan dengan adonan kerupuk yang beratnya $8 \mathrm{Kg}$, menggunakan kecepatan 200 Rpm (Radian Per Menit), dengan perbandingan antara tradisional dan alat sistem tekanan mekanik berbasis mikrokontroler AT-mega 16, dan hasilnya alat lebih cepat menyelesaikan satu tabung adonan. Dengan daya listrik yang dibutuhkan 60 watt, dengan perhitungan Watt $=$ Tegangan X Arus, Watt $=12 \mathrm{~V} \mathrm{X} 5 \mathrm{~A}=60$ Watt. Gambar 6 menunjukkan alat yang telah dikembangkan.

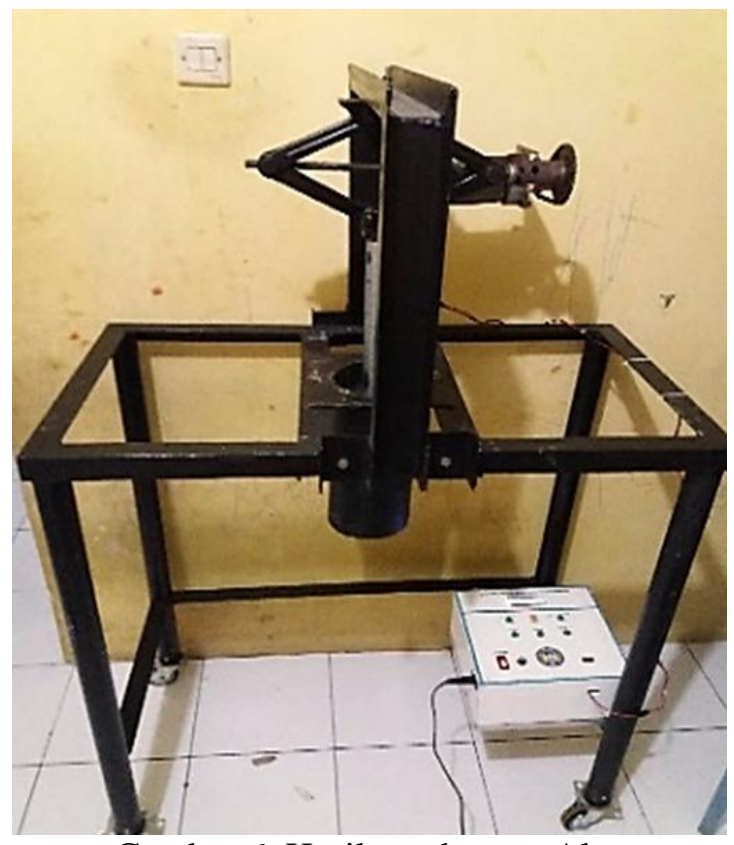

Gambar 6. Hasil pembuatan Alat

Uji coba alat dilakukan di Home Industry Barokah di Tuban Jawa Timur, dan hasil cetakan kerupuk pelompong terlihat seperti gambar 7 . 


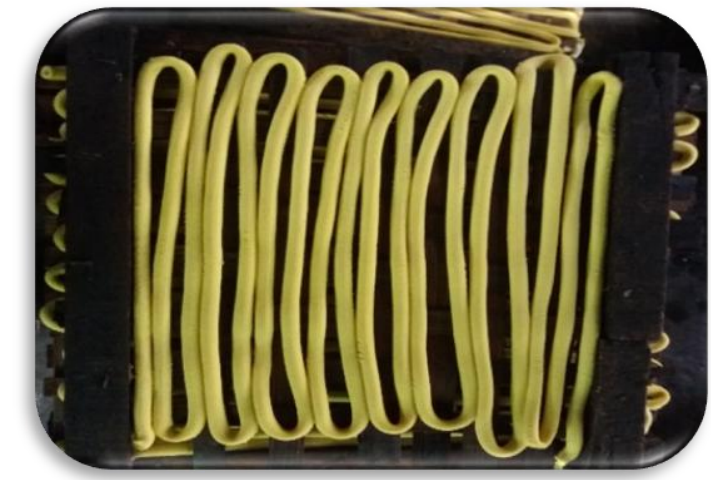

Gambar 7. Hasil Cetakan Kerupuk Pelompong

\section{SIMPULAN}

Berdasarkan hasil pengujian yang telah dilakukan terhadap Sistem Tekanan Mekanik Berbasis Mikrokontroler AT-Mega 16 Untuk Pembuat Kerupuk Pelompong Guna Menunjang Produksi Home Industry Barokah di Tuban Jawa Timur, maka dapat disimpulkan: (1) Pengembangan perangkat keras sistem tekanan mekanik berbasis mikrokontroler AT-Mega 16 dengan cara memodifikasi dongkrak mekanik disambungkan dengan Motor DC di las, kemudian merancang frame yang terbuat dari besi berbentuk tabung dan siku untuk menyambungkan membentuk rangka dengan cara pengelasan, lalu membuat rangkain sistem AT-mega 16, Rangkain Power supply, driver motor dan membuat box kontrol sistem;

(2) Pengembangan perangkat lunak sistem tekanan mekanik berbasis mikrokontroler ATMega 16 dengan cara membuat program bahasa $\mathrm{C}$ dengan software CVAVR untuk mengatur kerja dari sistem tekanana mekanik; (3) Unjuk kerja dan kelebihan dari Sistem Tekanan Mekanik Berbasis Mikrokontroler AT-Mega 16 Untuk Pembuat Kerupuk Pelompong Guna Menunjang Produksi Home Industry Barokah di Tuban Jawa Timur,secara keseluruhan sudah berfungsi dengan baik dan sesuai dengan kondisi di home industry Barokah, keunggulan sistem ini cukup 1 orang untuk mencetak (membuat) kerupuk pelompong, dibandingnkan dengan alat tradisional yang ada di home industry Barokah untuk mencetak perlu 2 orang untuk mengerjakan, secara efesiensi waktu sistem tekanan mekanik ini lebih cepat dengan selisih rata-rata 3 menit untuk menyelesaikan cetakan per tabung adonan. Berdasarkan keterbatasan kemampuan dan waktu, penulis mengakui masih adanya kekurangan dalam pengerjaan alat yang dibuat ini, maka dari itu penulis menyarankan sebagai berikut: (1) Penggunaan dongkrak yang sudah di modifikasi sebaiknya diganti dengan dongkrak elektrik yang sudah ada motornya sehingga putarannya center; dan (2) Penggunaan tabung adonan bisa diganti dengan alumunium atau bahan yang lain supaya anti karat.

\section{DAFTAR RUJUKAN}

Agus Purnama ( 2012 ). Teori motor DC dan jenis-jenis motor DC. Diambil tanggal 17 Maret 2017 dari http://elektronikadasar.web.id/teori elektronika/teorimotor-dc-dan-jenis-jenismotor-dc/

Agus Purnama. (2013). Elektronika Dasar: LCD (Liquid Crystal Display). Diambil tanggal 17 Maret 2017 dari http://elektronika-dasar.web.id/lcdliquid-cristal-display/

Asim Gurnawa. (2010) Jendela IPTEK : Gaya \& Gerak.Cetakan Pertama.PT. Balai Pustaka.Jakarta

Heri Andrianto. (2008). Pemrograman Mikrokontroler AVR ATmega16, Bandung: Informatika.

Immersa Lab (2013), Pengenalan CodeVision AVR. Diambil tanggal 12 Agustus 2016 dari www.immersalab.com/pengenalan-codevision-avr.htm

Lab Elektronika (2016). High current motor driver H-bridge module IBT-2 menggunakan arduino. Diambil tanggal 17 Maret 2017 dari http://www.labelektronika.com/2016/09 
/high-current-motor-driver-Ibt-2arduino.html

Syahe, M. Khaidir (2014). Rancang Bangun Dongkrak gunting elektrik pada mobil (perawatan dan perbaikan). Politeknik Negeri Sriwijaya
Zona Elektro. (2014). Refrensi Belajar Elektronika Online: Rangkain Power supply. Diambil tanggal 17 Maret 2017 dari http://zonaelektro.net/rangkaianpower-supply/ 